Please ensure that your abstract fits into one column on one page and complies with the Instructions to Authors

available from the Abstract Submission web page.

\title{
Marine Animal-Sediment Interactions Under Climate Change - Biogeochemical Consequences in the 21st Century
}

ThOMAS S. BIANCHI ${ }^{1 *}$, ROBert C. AlLeR ${ }^{2}$, Trisha ATWOOD $^{3}$, Craig BroWN ${ }^{4}$, LuIS BuATOIS ${ }^{5}$, Lisa A. LEVIN $^{6}$, JEFFREY S. LEVINTON ${ }^{7}$, JACK J. MIDDELBURG ${ }^{8}$, ELISE S. MORRISON ${ }^{1}$, PIERRE REGNIER ${ }^{9}$, MichaEL R. SHIELDS ${ }^{10}$, PAUl V.R. SNELGROVE ${ }^{11}$, ERIK E. SOTKA ${ }^{12}$, AND RYAN R.E. STANLEY ${ }^{13}$

${ }^{1}$ University of Florida, Gainesville, FL USA; tbianchi@ufl.edu, emorrison@ufl.edu

${ }^{2}$ Stony Brook University, Stony Brook, NY, USA; robert.aller@stonybrook.edu

${ }^{3}$ Utah State University, Logan, UT, USA; trisha.atwood@usu.edu

${ }^{4}$ Dalhousie University, Halifax, CA; Craig.Brown@dal.ca

${ }^{5}$ University of Saskatchewan, Saskatoon, SK, CA; luis.buatois@usask.ca

${ }^{6}$ Scripps Institution of Oceanography, La Jolla, CA, USA; llevin@ucsd.edu

${ }^{7}$ Stony Brook University, Stony Brook, NY, USA; jeffrey.levinton@stonybrook.edu

${ }^{8}$ Utrecht University, Utrecht,NL; J.B.M.Middelburg@uu.nl

${ }^{9}$ Université Libre de Bruxelles, Brussels, BE; Pierre.Regnier@ulb.ac.be

${ }^{10}$ Texas A\&M University, College Station, TX, USA; mshields@tamu.edu

${ }^{11}$ Memorial University of Newfoundland, St John's, CA; psnelgrove@mun.ca

${ }^{12}$ College of Charleston, Charleston, SC, USA; SotkaE@cofc.edu

${ }^{13}$ Bedford Institute of Oceanography, Dartmouth, Nova Scotia, CA; Ryan.Stanley@dfo-mpo.gc.ca

As we observe poleward redistribution of coastal taxa in response to climate warming, and functional responses to ocean acidification and deoxygenation, interest has grown globally with coupled responses in biogeochemical processing. Here, we focus on the role of benthic macrofauna on global biogeochemical cycles, with an emphasis on carbon dynamics. In particular, we explore carbon consumption uptake regulated indirectly (via predation on microbes) and directly (via the environment (ecosystem engineering, bioturbation, bioirrigation), and how these gradients create critical zones that influence biological productivity, distribution, phenotypic plasticity, and/or evolution. 